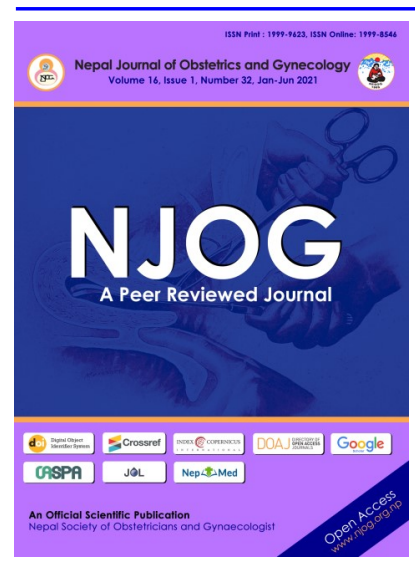

CORRESPONDENCE

Dr. Alka Shrestha

Paropakar Maternity and Women's Hospital, Thapathali, Kathmandu, Nepal

Email:

shresthaalka0@gmail.com Phone: + 977-9841789820

Received: May 1, 2020

Accepted: May 202021

\section{Citation:}

Shrestha A. Clinical profile of Female Urinary Incontinence: A Hospital Based Study. Nep J Obstet Gynecol. 2021;16(32):120 -123. DOI: https:// doi.org/10.3126/ njog.v16i1.37917

\title{
Clinical profile of Female Urinary Incontinence: A Hospital Based Study
}

\author{
Alka Shrestha \\ Paropakar Maternity and Women's Hospital, Kathmandu, Nepal
}

\section{ABSTRACT}

Aim: To determine the prevalence of urinary incontinence of women attending gynaecology outdoor patient department.

Method: It is a prospective cross sectional study conducted at Paropakar Maternity and Women's Hospital for three months. Types of incontinence, their presentation, associated factors, age and parity were the variables studied. Data were analyzed by descriptive statistics.

Results: Out of 950 gynaecological out-patients, 97 had urinary incontinence $(10.2 \%) ; 34.1 \%$ were in $50-59$ years and $37.2 \%$ were multipara. Stress urinary incontinence (SUI) was the most common incontinence $(56.7 \%)$ followed by mixed urinary incontinence $(22.7 \%)$ and urge urinary incontinence $(20.6 \%)$. Common complaints were leakage during coughing (63.6\%) and sneezing $(18.2 \%)$ in SUI; urgency and frequency were main problem in mixed and urge urinary incontinence. Three-fourth cases had associated medical conditions and rest had gynecological factors.

Conclusions: Urinary incontinence is common in the fifth decade of life of women and more than half had stress incontinence.

Keywords: incontinence, mixed, stress, urge, urinary

\section{INTRODUCTION}

Urinary incontinence is a common problem among women of all age groups which may affect her physical, social and mental wellbeing; and significantly changes her quality of life. ${ }^{1-3}$ However, only one- third of them seek for medical care. ${ }^{4}$ Globally, there is substantial variation in prevalence of urinary incontinence. It affects men and women with higher prevalence in women affecting 15 $-55 \% .^{5}$ One study conducted in $\mathrm{Ne}$ pal reported $50.6 \%{ }^{6}$ whereas it was $21.87 \%^{7}$ in an Indian study. Stress urinary incontinence (SUI), urge urinary incontinence (UUI) and mixed urinary Incontinence (MUI) are main three problems women are usually presented with. While prevalence of SUI peaks at fifth decade, UUI and MUI increase with age. ${ }^{1,2}$ The most prevalent is SUI (51\%) followed by MUI (39.0\%) and UUI (10.0\%). ${ }^{5}$

SUI occurs in the presence of increased abdominal pressure without perception of micturition desire. Factors associated for this condition are aging, pregnacy, vaginal delivery, obesity, post hysterectomy pelvic organ prolapse, hypertension, diabetes Mellitus and hypoestrogenism. ${ }^{2,3,5}$

In UUI, there is sudden urge to urinate and there is no control over the detrusor muscle. Recurrent urinary tract infection is independently associated with UUI. Similarly, increased BMI and advanced age are also associated with UUI. Additionally, women, whose mother or sisters are incontinent, are more likely to develop SUI and MUI. Moreover, Parkinson's disease or stroke can lead to neurogenic detrusor overactivity. ${ }^{5}$

Urinary incontinence in woman with MUI is associated with increased abdominal pressure and also prior or simultaneously with urgency without abdominal effort. The pathological mechanism that generates symptoms of SUI and UUI in the same patient is unknown. ${ }^{5}$ 
Women with UI are usually presented with leakage during coughing, sneezing, weight lifting or frequency, urgency and nocturia causing significant trouble in performing day to day activities. Urinary incontinence is common but significantly under reported condition. Hence, this study aims to study the prevalence, types and associated factors with this bothersome condition so that the findings of this study may be used to screen, diagnose and manage in order to improve the quality of life of women.

\section{METHODS}

This prospective cross-sectional study was conducted at Paropakar Maternity and Women's Hospital for three months February to May 2021. Pregnancy, postpartum cases and age under 20 years were excluded from the study. Ninety seven cases who met the criteria were taken with informed consent. Cases were analyzed in terms of age, parity, type of urinary incontinence and associated risk factors using MS Excel and SPSSv25.

\section{RESULTS}

During study period, 950 women attended Gynae OPD and 97 had urinary incontinence $(10.2 \%)$. Majority were between $50-59$ years $(n=33 ; 34.1 \%)$ and para three $(n=36 ; 37.2 \%)$. [Table-1]

Table-1: Distribution according to age and parity $(\mathrm{N}=97)$

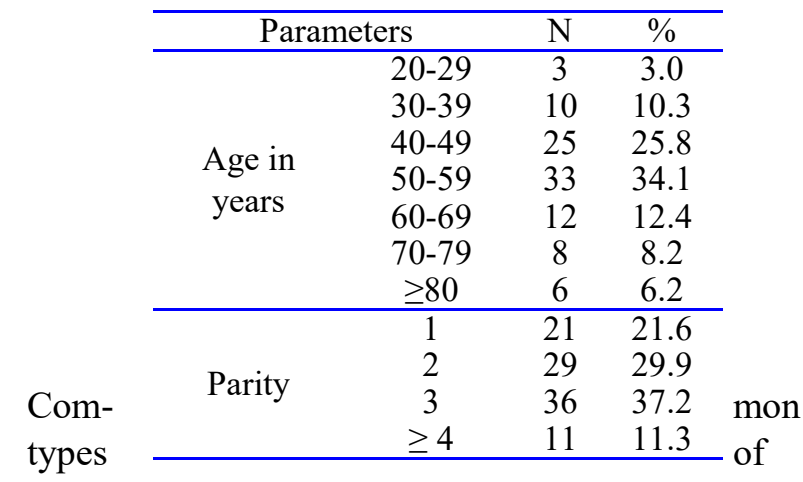

urinary incontinence were stress, mixed type and urge in order.[Figure-1]

Urinary leakage during cough was the main complaint of women with stress incontinence followed by the sneezing; urgency in urge urinary incontinence; and cough and frequency in mixed type. [Table-3]

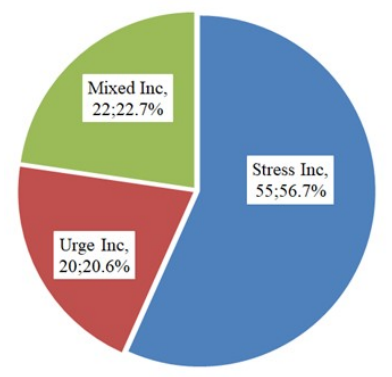

Figure-1:

Types of

Urinary Incontinence $(\mathrm{N}=97)$

Table-3: Presentation of Urinary Incontinence

\begin{tabular}{llcc}
\hline Types & Presentation & $\mathrm{N}$ & $\%$ \\
\hline & Cough & 35 & 63.6 \\
Stress & Sneezing & 10 & 18.2 \\
$(\mathrm{~N}=55)$ & Weight Lifting & 5 & 9.1 \\
& Posture Changing & 3 & 5.5 \\
& Sexual Activity & 2 & 3.6 \\
\hline \multirow{2}{*}{ Urge } & Urgency & 8 & 40.0 \\
$(\mathrm{~N}=20)$ & Frequency & 6 & 30.0 \\
& Nocturia & 6 & 30.0 \\
\hline \multirow{2}{*}{ Mixed } & Cough, Frequency & 12 & 54.5 \\
$(\mathrm{~N}=22)$ & Cough, Frequency, Noctu- & 8 & 36.4 \\
& ria & & \\
& Cough, Frequency, Urgency & 2 & 9.1 \\
\hline
\end{tabular}

$$
(\mathrm{N}=97)
$$

Medical factors were associated in three-fourth and gynecological factors in one-fourth of cases. [Table-4]

Table-4: Factors associated with urinary inconti-

\begin{tabular}{|c|c|c|c|}
\hline \multicolumn{2}{|c|}{ Associated factors } & $\mathrm{N}$ & $\%$ \\
\hline \multirow{6}{*}{ 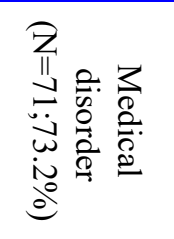 } & COPD & 10 & 10.3 \\
\hline & DM & 15 & 15.5 \\
\hline & HTN & 20 & 20.6 \\
\hline & Neurological disorder & 3 & 3.0 \\
\hline & Psychiatric disorder & 3 & 3.0 \\
\hline & UTI & 20 & 20.6 \\
\hline \multirow{3}{*}{ 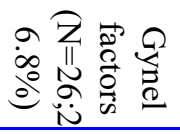 } & POP & 15 & 15.5 \\
\hline & Post TAH & 6 & 6.0 \\
\hline & Post VH & 5 & 5.3 \\
\hline
\end{tabular}

nence $(\mathrm{N}=97)$

\section{DISCUSSION}

Urinary incontinence (UI) is common but significantly under reported. It affects women of all age groups. ${ }^{1}$ Its prevalence varies. The major reason for this variation is the way urinary incontinence is defined. ${ }^{1}$ In the present study, the prevalence of UI is $10.2 \%$. This is much lower than the findings of studies done by MinassianVA ${ }^{1}(25.0 \%)$, Regmi 
$\mathrm{MC}^{6} \quad(50.6 \%)$,Singh $\quad \mathrm{U}^{7} \quad(21.87 \%)$,Jolleys $\quad \mathrm{JV}^{8}$ $(41.0 \%)$, Masenga $\mathrm{GG}^{9}(42.0 \%) .{ }^{1,6-9}$ Such difference may be related with culture difference in the perception of UI and willingness to report UI as well as methodological differences.

Age is the independent risk factor for UI. ${ }^{1}$ This study found the majority of women $(\mathrm{n}=59,34.1 \%)$ with UI belong to age group 50-59 years. Such finding was also reported by Minassian VA. ${ }^{1}$ However, Regmi $M^{6}$ and Singh $\mathrm{U}^{7}$ reported that its prevalence increases 40 years above.

Similarly, very high prevalence of UI $(60.0 \%)$ was reported by JolleysJV in the age group 45-54 years. ${ }^{8}$ Many studies reported that prevalence of UI increases with increasing parity. ${ }^{7-11}$ The presentstudy found highest number of UI $(n=36,37.2 \%)$ in multiparity (para 3). Such findings were also reported by studies of Masenga $\mathrm{GG}^{9}$, Zago $\mathrm{AC}^{10}$, Prabhu $\mathrm{SA}^{11}$ and $\mathrm{Wu} \mathrm{JM}^{12}{ }^{12}$ Similarly, Jolleys $\mathrm{JV}^{8}$ also reported that there is linear increase in UI with increasing parity.

The most common UI in this study was SUI $(n=55$; $56.7 \%)$ followed by MUI $(\mathrm{n}=22 ; 22.7 \%)$ and UUI $(n=20 ; 20.6 \%)$. Similar observation was also reported by Mota RL. ${ }^{5}$ However, much higher incidence of SUI was reported by Singh U (68.4\%) but less UUI (15.8\%) and MUI $(15.8 \%){ }^{7}$ In contrast to this, Regmi $\mathrm{MC}^{6}$ reported lower incidence of SUI $(40.0 \%)$ and higher incidence of UUI $(60.0 \%)$. Similarly, Wood $\mathrm{L}^{3}$ reported SUI in $10.0 \%$, UUI in $7-33 \%$ and MUI in $14-61 \%$.

This study showed that urine leakage during coughing $(63.6 \%)$ and sneezing $(18.2 \%)$ were the main complaints of women with SUI; urgency in $40.0 \%$ in UUI; and cough and urgency in $54.5 \%$ in MUI. However, WU JM et al in his study reported that urgency $(51.0 \%)$ and nocturia $(43.0 \%)$ were chief complaints inwomen with UUI. ${ }^{12}$ Such clinical presentations are mentioned in many studies but their frequencies are not well quoted.

In this study, 71 (73.2\%) women with UI had medical disorders like hypertension and urinary tract infection being the leading factors $(n=20,20.6 \%$, each). Such association was also reported by Sing $\mathrm{U}^{7}$, Jolleys $\mathrm{JV}^{8}$, Mesenga $\mathrm{GG}^{9}$ and Prabhu $\mathrm{SA}^{11}$ and Berghmans. $^{13}$

This study observed that the $15(15.5 \%)$ women with UI had pelvic organ prolapse (POP). De Laney et al also showed that POP potentially leads to UI. Moreover, some authors consider that this association is probably, due to similar patholphysiology. ${ }^{14}$

This study also found that 11 women $(11.3 \%)$ reported UI following hysterectomy. Similarly, Wu $\mathrm{JM}$ et al also reported that the cumulative incidence of new onset UI following hysterectomy after 4 year of hysterectomy was $16.7 \%$ (SUI $16.1 \%$, UUI
This study also found that 11 women $(11.3 \%)$ reported UI following hysterectomy. Similarly, Wu $\mathrm{JM}$ et al also reported that the cumulative incidence of new onset UI following hysterectomy after 4 year of hysterectomy was $16.7 \%$ (SUI $16.1 \%$, UUI $13.8 \%$, MUI $13.7 \%)^{12}$

\section{CONCLUSIONS}

Prevalence of urinary incontinence peaks in the fifth decade of life and stress urinary incontinence is the most common type of presentation. Most of the incontinence is associated with medical disorders than gynecological factors.

\section{ACKNOWLEDGEMENT}

I acknowledge my mentors Madhu Shrestha, Ganesh Dangal and Gehanath Baral for their valuable input in preparing the manuscript.

\section{REFERENCES}

1. Minassian VA, Stewart WF, Wood GC. Urinary incontinence in women: variation in prevalence estimates and risk factors. Obstet Gynecol. 2008;111(2):324-31.

2. Aoki Y, Brown HW, Brubaker L, Cornu JN, Daly JO, Cartwright R. Urinary incontinence in women. Nature Rev Dis Primers. 2017;3(1):120.

3. Wood LN, Anger JT. Urinary incontinence in women. Br Med J. 2014;349.

4. Rashid P, Santiagu SK, Arianayagam M, Wang A. Urinary incontinence: pathophysiology and management outline. Aus Fam Physician. 2008;37(3).

5. Mota RL. Female urinary incontinence and sexuality. Int Braz J Urol. 2017;43(1):20-8.

6. Regmi MC, Uprety D, Poonam M. Prevalence of urinary incontinence among gynecological admissions at tertiary care hospital in eastern Nepal. Health Renais. 2012;10(1):16-9.

7. Singh U, Agarwal P, Verma ML, Dalela D, Singh N, Shankhwar P. Prevalence and risk factors of urinary incontinence in Indian women: A hospital-based survey. India J Urol. 2013;29(1):31.

8. Jolleys JV. Reported prevalence of urinary incontinence in women in a general practice. $\mathrm{Br}$ Med J. 1988;296(6632):1300-2. 
9. Masenga GG, Shayo BC, Msuya S, Rasch V. Urinary incontinence and its relation to delivery circumstances: A population-based study from rural Kilimanjaro, Tanzania. PloS one. 2019;14 (1):e0208733.

10.Zago AC, Fambrini MA, Silva EP, Vitta AD, Conti MH, Marini G. Prevalence and knowledge of urinary incontinence and possibilities of treatment among low-income working women. Fisioterapia em Movimento. 2017;30:151-9.

11.Prabhu SA, Shanbhag S. Prevalence and risk factors of urinary incontinence in women residing in a tribal area in Maharashtra, India.2017:13 (2):151-9.
12.Wu JM, Stinnett S, Jackson RA, Jacoby A, Learman LA, Kuppermann M. Prevalence and incidence of urinary incontinence in a diverse population of women with noncancerous gynecologic conditions. Fem Pelvic Med Reconst Surg. 2010;16 (5):284.

13.Berghmans B,Cardozo L,Staskin D. Physotherapy for Urinary Incontinence.Textbook of Female Urology \&Urogynecology.2017; 4th edition:477-490

14.Menefee SA, Nygarrd I.Lower Urinary Tract Disorders.Berek \&Novak's Gynecology. $2115 ; 15^{\text {th }}$ edition: $862-902$ 